\title{
Toxoplasmosis testicular: un caso raro de masa testicular
}

\author{
Barreto F, Hering F, Dall'oglio MF, Martini Filho D, Campagnari JC, Srougi M. \\ Hospital Beneficência Portuguesa, São Paulo, Brasil.
}

Actas Urol Esp. 2008;32(6):666-668

\section{RESUMEN}

TOXOPLASMOSIS TESTICULAR: UN CASO RARO DE MASA TESTICULAR

El Toxoplasma gondii es un protozoario intracelular que infecta aves y mamíferos. La infección aguda es asintomática en pacientes inmunocompetentes. En pacientes con deficiencia inmunológica (síndrome de la inmunodeficiencia adquirida, linfomas o pacientes sometidos a terapia con corticoides para prevención de rechazo de transplante de órganos) la infección puede ser fatal.

Nosotros describimos un caso poco común de toxoplasmosis testicular en paciente sometido a transplante renal hace 6 años con serología negativa para el virus VIH y sin toxoplasmosis sistémica.

Palabras clave: Toxoplasmosis. Síndrome de inmunodeficiencia adquirida. Neoplasia testicular. Trasplante renal. Deficiencia inmunológica.

\section{ABSTRACT \\ TESTICULAR TOXOPLASMOSIS: A RARE CASE OF MASS TESTICULAR}

Toxoplasma gondii is an intracellular protozoan infecting birds and mammals. Acute infection is asymptomatic in immune competent people. For immune deficient patients (acquired immune deficiency syndrome, lymphoma patients or those under steroids to prevent organ transplantation rejection) infection may be lethal.

We describe an uncommon case of testicular toxoplasmosis in patient under steroids after organ transplantation with no positive serum test for HIV and/or systemic toxoplasmosis.

Keywords: Toxoplasmosis. Acquired immunodeficiency syndrome. Testicular neoplasia. Kidney transplantation. Immune suppression.

$\mathrm{E}$ Toxoplasma gondii es un protozoario intracelular que infecta aves y mamíferos. La infección aguda es asintomática en pacientes inmunocompetentes. En pacientes con deficiencia inmunológica (sindrome de la inmunodeficiencia adquirida, linfomas o pacientes sometidos a terapia con corticoides para prevención de rechazo de transplante de órganos) la infección puede ser fatal ${ }^{1,3}$.

Nosotros describimos un caso poco común de toxoplasmosis testicular en paciente sometido a transplante renal hace 6 años con serología negativa para el virus VIH y sin toxoplasmosis sistémica.

\section{CASO CLÍNICO}

Paciente masculino, 60 años, sometido a transplante renal hace 6 años, en uso de prednisona 10 $\mathrm{mg}$ al día y micofenolato mofetil 1,5 mg al día, con historia de dolor en el testículo derecho. Presentaba tests serológicos negativos para sífilis, virus de la inmunodeficiencia adquirida, cisticercosis, toxoplasmosis, histoplasmosis, viruela zoster, herpes tipos 1 y 2, citomegalovirus, paracoccidiomicosis, candidiasis y aspergilosis. Los marcadores tumorales como alfa fetoproteína 2,4; DHL 361 y beta-HCG 0,1 , estaban normales. La ultrasonografía de bolsa 
testicular evidenció una tumoración sólida ocupando todo el testículo derecho con aumento de la vascularización. El testículo izquierdo era de apariencia normal. Tomografías computadorizadas de tórax y abdomen sin evidencia de lesión metastásica o linfonodo aumentado de tamaño, respectivamente. El paciente fue sometido la orquiectomía radical derecha, debido a la sospecha diagnóstica de un proceso neoplásico envolviendo el testículo derecho. La superficie de corte, en la patología, reveló una masa tumoral substituyendo todo el testículo, constituida por tejido firme y grisáceo, teniendo en medio áreas amarillentas de aspecto necrótico.

La microscopia reveló un proceso inflamatorio caracterizado por infiltrado linfohistiocitario denso con fibrosis y extensas áreas de necrosis, bien como numerosas estructuras parasitarias con caracterís- ticas de Toxoplasma gondii (Fig. 1). El paciente evolucionó bien, en el postoperatorio, y tuvo alta hospitalaria en el primer día de postoperatorio.

\section{DISCUSIÓN}

El toxoplasma gondii puede infectar humanos con una prevalencia arriba del $70 \%$ en los Estados Unidos $^{1}$. Nistal et al. relataron evidencias de individuos expuestos a parasitosis (más del 50\%) en varias comunidades $^{2}$. Crider et al. relataron incidencia de infección por toxoplasma gondii en aproximadamente un $10 \%$ de pacientes ancianos, con manifestaciones clínicas primariamente relacionadas al sistema nervioso central y meningoencefalitis ${ }^{3}$. Sin embargo, la infección testicular por el toxoplasma gondii es extremadamente poco común, hasta mismo en pacientes inmunocomprometidos ${ }^{1-3}$.

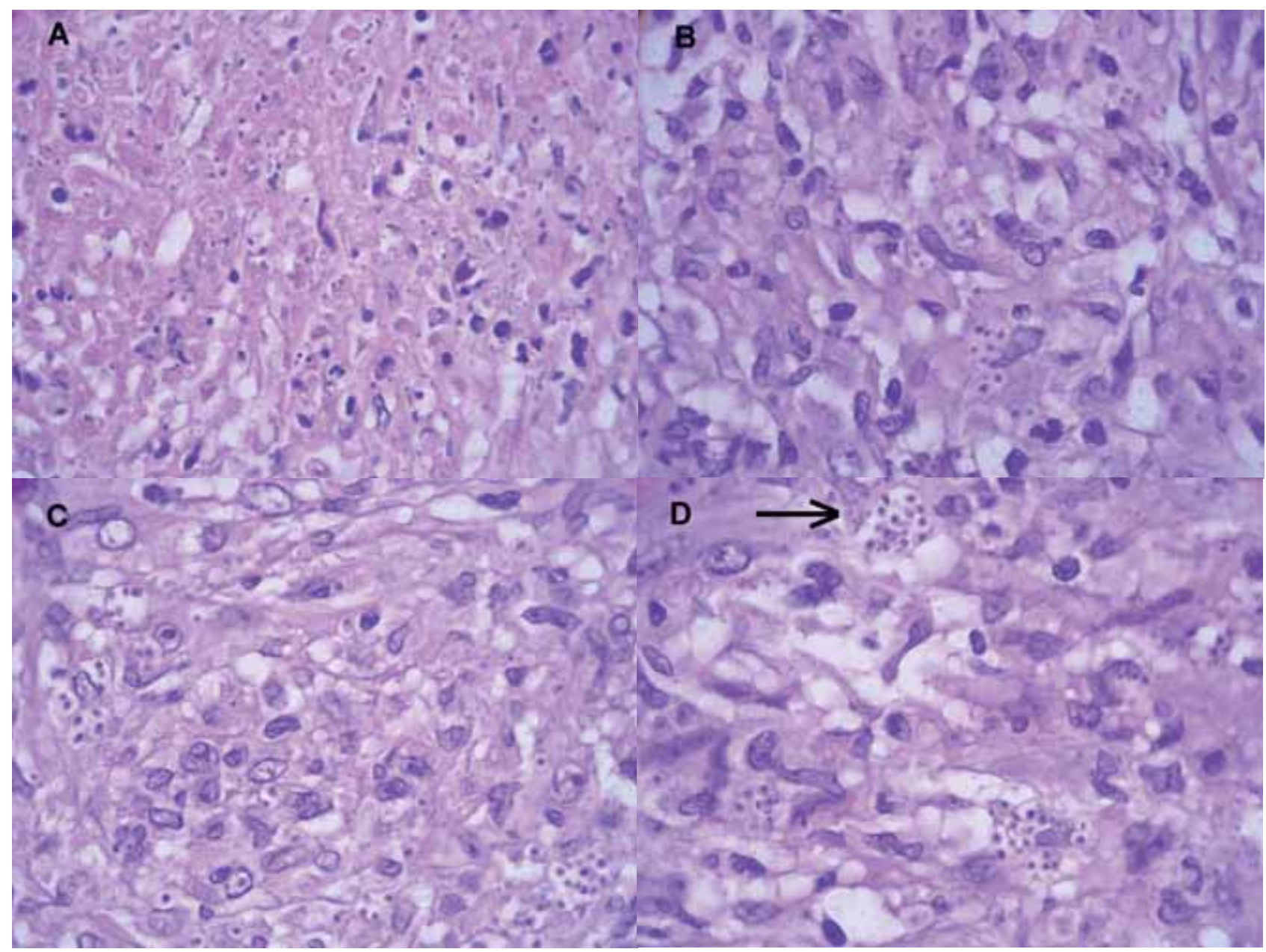

FIGURA 1. A: necrosis eosinofílica; B, C y D: presencia de histiocitos con vacúolos citoplasmáticos y nidos de corpúsculos con caracteristicas de toxoplasma gondii (H.Y. - 480x). 


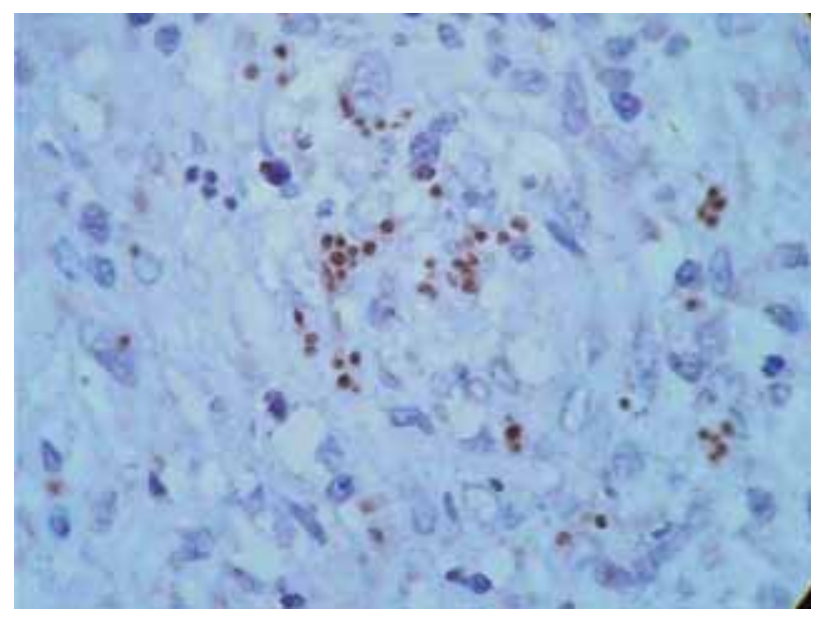

FIGURA 2. Corpúsculos marrones coloreados con técnica inmunohistoquimica especifica para el toxoplasma gondii $(H . Y-480 x)$.

La toxoplasmosis sistémica es diagnosticada a través de tests séricos, como anticuerpos IgG y IgM, aunque el diagnóstico puede ser no-conclusivo debido a los bajos títulos de estos anticuerpos en pacientes inmunocomprometidos ${ }^{3}$.
La orquiectomía inguinal fue indicada por la posibilidad de neoplasia testicular. El estudio inmunohistoquímico reveló toxoplasmosis testicular (Fig. 2).

\section{REFERENCIAS}

1. Haskel Ll, Fusco MJ, Ares L, Sublay B. Case Report: Disseminated Toxoplasmosis Presenting as Symptomatic Orchitis and Nephrotic Syndrome. Am J Med Sciences 1989; 298(3):185-190.

2. Nistal M, Santana A, Paniaqua R, Palacios J. Testicular toxoplasmosis in two men with the acquired immune deficiency syndrome. Arch Pathol Lab Med 1986; 110:744-746.

3. Crider SR, Horstman WG, Massey GS. Toxoplasma orchitis: Report of a case and a review of the literature. Am J Med 1998; 85:421-424.

\section{Correspondencia autor: Dr. F. Barreto}

Hospital Beneficência Portuguesa. Clinica Urológica $1^{\circ}$ subsolo Rua Maestro Cardim, 769 - Bela Vista. São Paulo. Brasil SP-CEP 01323-900. Tel.: (11) 3505-1000

E-mail autor: fjbarreto@terra.com.br

Información artículo: Nota clínica

Trabajo recibido: febrero 2006

Trabajo aceptado: abril 2007 